\title{
RAEDER PARATRIGEMINAL SYNDROME IN A PATIENT WITH A MASS LESION IN THE MAXILLARY SINUS
}

\author{
V. Kirkova ${ }^{1}$, A. Andreeva ${ }^{1}$, S. Cherninkova ${ }^{1}$, I. Tournev ${ }^{1}$, I. Dimitrov ${ }^{2}$, A. Oscar ${ }^{1,3}$ \\ ${ }^{1}$ Clinic of Neurology, Alexandrovska University Hospital, Sofia, Bulgaria \\ ${ }^{2}$ First Clinic of Neurology, Sveta Marina University Hospital, Varna, Bulgaria \\ ${ }^{3}$ Clinic of Ophthalmology, Alexandrovska University Hospital, Sofia, Bulgaria
}

\section{SUMIMARY}

Raeder paratrigeminal syndrome is a rare syndrome, characterized by severe unilateral facial pain and headache in the distribution of the ophthalmic division of the trigeminal nerve in combination with ipsilateral oculosympathetic palsy or Horner syndrome. We describe a case of a 65 -year-old male patient with a large tumor in the right maxillary sinus who presented with the rare Raeder syndrome. facial pain

Key words: Raeder syndrome, oculosympathetic palsy,

\section{INTRODUCTION}

Raeder paratrigeminal syndrome is a rare syndrome, characterized by severe unilateral facial pain and headache in the distribution of the ophthalmic division of the trigeminal nerve in combination with ipsilateral oculosympathetic palsy or Horner syndrome. $(3,5,7)$ It was first described by the Norwegian ophthalmologist J.G. Raeder in 1918 in a young male patient with unilateral periocular pain combined with ipsilateral miosis and ptosis, and with slight objective signs of trigeminal nerve involvement. (1) Autopsy demonstrated a tumor at the base of the skull in the middle cranial fossa. Raeder used the term "paratrigeminal" for the reported clinical picture. Later case reports by Raeder and other authors have included patients experiencing a more benign clinical course, some with spontaneous remissions, with unilateral periocular pain and ipsilateral signs of oculosympathetic paresis. $(1,2,6)$ Raeder syndrome has been associated with several conditions, including head trauma, hypertension, vasculitis, migraine headaches, parasellar mass lesions, and internal carotid artery dissection or aneurysm, and sometimes Lyme disease. $(4,5,7,8,9)$

\section{CASE DESCRIPTION}

We describe the case of a 65 -year-old male patient who presented with facial pain involving the right trigeminal nerve and ipsilateral ptosis, together with a bloody discharge from the right nostril in the last two months. Neurological examination revealed a classical Raeder syndrome - presented with trigeminal neuralgia, involving the ophthalmic and maxillary divisions of the right $\mathrm{V}^{\text {th }}$ cranial nerve and partial Horner syndrome (right ptosis without miosis). Thorough neuroophthalmological examination showed mild right ptosis, pupils with preserved normal reactions to light and near response, normal ocular movements (no hypofunction of the eye muscles). The ophthalmoscopic findings included optic discs with clear borders, normal colour and deep excavations, blood vessels having mild angiosclerotic changes and normal retinas. There was mild increase of the intraocular pressure of both eyes.

Anterior rhinoscopy was performed showing tumor formation with grainy surface that filled the right nasal meatus.

Brain MRI showed a large tumor mass in the right maxillary sinus with local invasion and dissemination in the epipharyngeal lymphatic collector (Fig. 1). The tumor mass was relatively hypointense on $\mathrm{T} 2$ and with intermediate intensity on T1, leading to expansion of the sinus and extensive destruction of its medial, upper and front walls. The inferior and medial right rectus muscles were displaced laterally and upwards, respectively. T2 hyperintense collections were present in the left maxillary sinus, in the right anterior ethmoidal cells, in the left sphenoidal and the right frontal sinuses. The right epipharyngeal recessus appeared obliterated by a mass which was relatively hypointense on $\mathrm{T} 2$ and remained confined to the pharyngeal mucous space. No other paracarotid lymphatic collectors seemed affected. No focal parenchymal brain lesions were found. Ventricular system, basal cisterns and convexital arrachnoid spaces were normal. The findings corresponded most likely to a tumor of the right maxillary sinus with local invasion and dissemination in the epipharyngeal lymphatic collector.

The patient was sent for surgery of the right maxillary sinus. Denker's operation was performed. Intraoperatively a grainy tumor formation was found, that occupied the right nasal meatus, the cavity of the right maxillary sinus, and invading the right orbit. Histology showed moderately differentiated basal cell carcinoma, staged T4N0M0.

Postoperative radiotherapy was recommended to the patient. 
After the complete surgical removal of the tumor all symptoms of the Raeder syndrome were resolved, with the patient feeling no pain and having no ptosis.

\section{DISCUSSION}

Unilateral oculosympathetic paresis and evidence of trigeminal nerve involvement are the two hallmark clinical features of the rare Raeder syndrome. While most cases are benign with spontaneous remissions, complex evaluation and neuroimaging are necessary to exclude secondary causes, particularly if parasellar nerve involvement is evident. With the present case we would like to emphasize that insignificant at first look clinical signs might be the presenting symptoms of a serious underlying disease. That is why thorough clinical examination in patients with mild ptosis is needed to ensure accurate and prompt diagnosis of possible serious diseases.

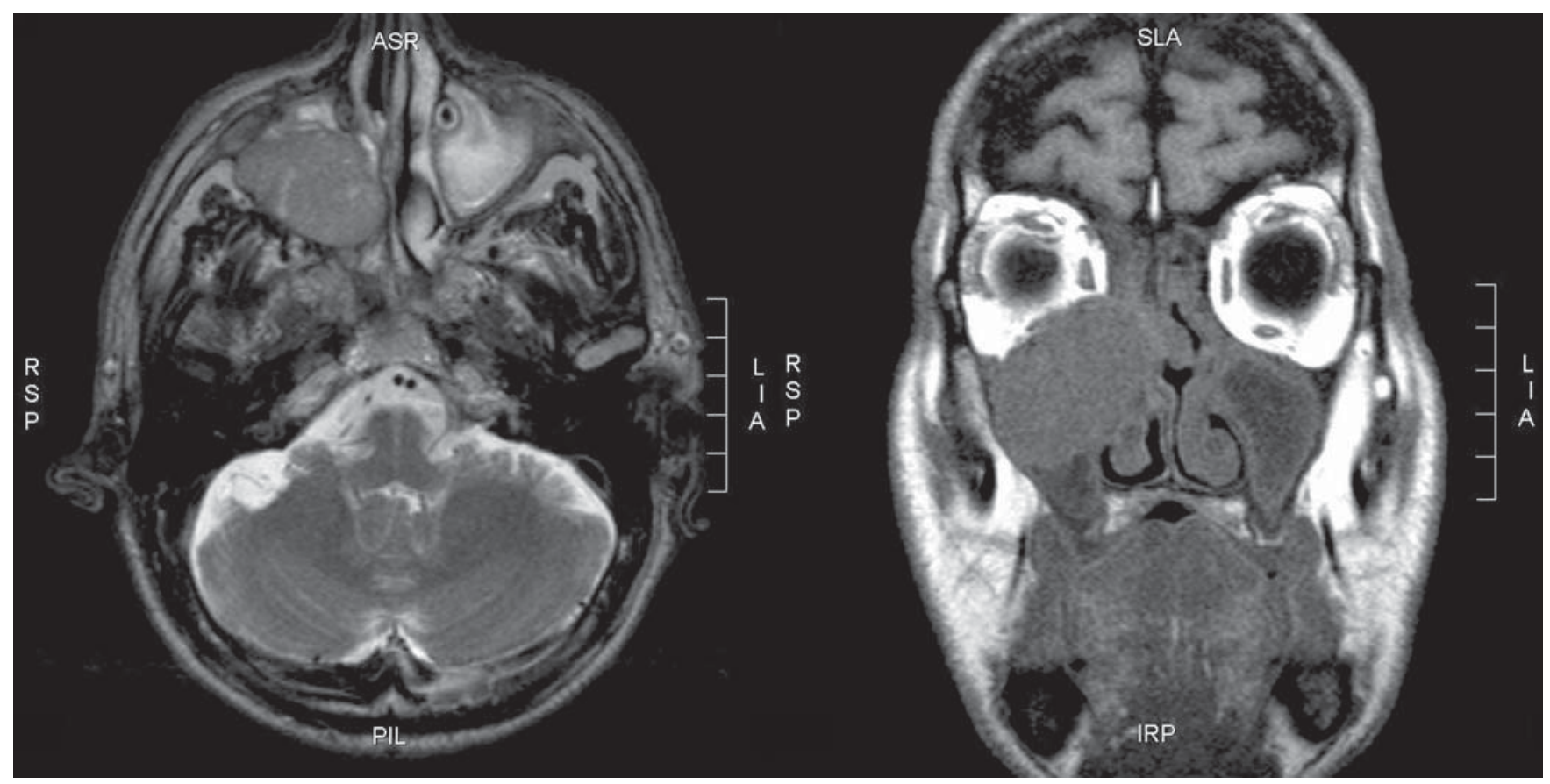

Fig. 1. Brain MRI: T2 axial (left) and T1 coronal (right) sections showing a large hypointense tumor mass in the right maxillary sinus.

\section{REFERENCES:}

1. Shoja, MM, Tubbs, RS, Ghabili, K, et al. Johan Georg Raeder (1889-1959) and Paratrigeminal Sympathetic Paresis. Childs Nerv Syst. 2010;26:373-376.

2. Murnane M, Proano L. Raeder's paratrigeminal syndrome: a case report. Acad Emerg Med. Sep 1996;3(9):864-7.

3. Grimson BS, Thompson HS. Raeder's syndrome. A clinical review. Surv Ophthalmol. Jan-Feb 1980;24(4):199-210.

4. Solomon S. Raeder syndrome. Arch Neurol. Apr 2001; 58(4):661-2.

5. Appen RE, Sturm RJ. Raeder's paratrigeminal syndrome. AnnOphthalmol. Sep 1978;10(9):1181-7.

6. Grimson BS, Thompson HS. Raeder's syndrome. A clinical review. Surv Ophthalmol. Jan-Feb 1980;24(4):199-210.

7. Goadsby PJ. Raeder's syndrome [corrected]: paratrigeminal paralysis of the oculopupillary sympathetic system. $J$ Neurol Neurosurg Psychiatry. Mar 2002; 72(3):297-9.

8. Koutsis G, Andreadou E, Matsi S, Evangelopoulos ME, Sfagos C. Benign Raeder syndrome evolving into indomethacin-responsive hemicranial headache. Headache. 2008 Nov-Dec; 48(10): 1534-6. Epub 2008 Jul 1.

9. Murphy MA, Szabados EM, Mitty JA. Lyme disease associated with postganglionic Horner syndrome and Raeder paratrigeminal neuralgia. J Neuroophthalmol. 2007 Jun;27(2):123-4.

10. Solomon S, Lustig JP. Benign Raeder's syndrome is probably a manifestation of carotid artery disease. Cephalalgia. $2001 \mathrm{Feb}$;21(1):1-11.

\section{Address for correspondence:}

Vyara Kirkova, MD

Clinic of Neurology, Alexandrovska University Hospital

1 Sv. Georgi Sofijski Str., 1431 Sofia, Bulgaria

E-mail: vyarakirkova@yahoo.com 